\title{
Fibronectin Type III Domain-Containing 5 Attenuates Liver Fibrosis Via Inhibition of Hepatic Stellate Cell Activation
}

\author{
Bing Zhou ${ }^{a}$ Li Ling ${ }^{a}$ Feng Zhang ${ }^{a}$ Tong-Yan Liu ${ }^{a}$ Hong Zhou ${ }^{a}$ \\ Xiao-Hong Qia Qi Chen ${ }^{b}$ Yue-Hua Lib Yu-Ming Kang ${ }^{c}$ Guo-Qing Zhu ${ }^{a, b}$

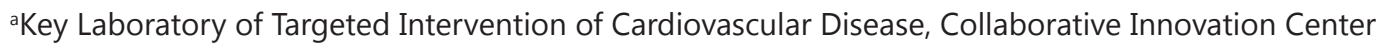 \\ of Translational Medicine for Cardiovascular Disease, and Department of Physiology, Nanjing Medical \\ University, Nanjing, 'Department of Pathophysiology, Nanjing Medical University, Nanjing, 'Department \\ of Physiology and Pathophysiology, Cardiovascular Research Center, Xi'an Jiaotong University School of \\ Medicine, Xi'an, China
}

\section{Key Words}

Fndc5 $•$ Liver fibrosis $\bullet$ Hepatic stellate cell $•$ Obesity $\bullet$ High fat diet

\begin{abstract}
Background/Aims: Fibronectin type III domain-containing 5 (FNDC5) protein is involved in the beneficial effects of exercise on metabolism. FNDC5 attenuates hepatic steatosis induced by high fat diet (HFD). Here, we examined the effects of FNDC5 on liver fibrosis and underline mechanisms. Methods: Experiments were carried out on wild-type and FNDC5 $1-$ mice, primary mouse hepatic stellate cells (HSCs) and human hepatic stellate cell line (LX-2). The mice were fed with HFD for 6 months to induce liver fibrosis. Oxidized low density lipoprotein (oxLDL) were used to induce the activation of hepatic stellate cells and fibrosis in mouse HSCs and human LX-2 cells. H\&E, Masson's trichrome staining and Sirius red staining were used for liver sections. Protein and mRNA expressions were evaluated with Western blot and RT-PCR, respectively. Results: FNDC5 deficiency aggravated the HFD-induced liver fibrosis and HSCS activation in mice. It exacerbated the HFD-induced inhibition of AMPK phosphorylation, upregulation of connective tissue growth factor (CTGF) and transforming growth factor- $\beta$ (TGF- $\beta$ ), and deposition of extracellular matrix (ECM) in liver of mice. Administration of FNDC5 attenuated oxLDL-induced AMPK deactivation, HSCs activation, CTGF and TGF- $\beta$ upregulation and ECM deposition in mouse HSCs. The beneficial effects of FNDC5 on oxLDL-induced AMPK dephosphorylation, HSCs activation and ECM deposition were prevented by the inhibition of AMPK with compound C in human LX-2 cells. However, the effects of FNDC5 on hepatic fibrosis in vivo in this study cannot be distinguished from its effects on adiposity and hepatic steatosis. Conclusions: FNDC5 deficiency aggravates HFD-induced liver fibrosis in mice. FNDC5 plays beneficial roles in attenuating liver fibrosis via AMPK phosphorylation-mediated inhibition of HSCs activation.




\section{Cellular Physiology Cell Physiol Biochem 2018;48:227-236 and Biochemistry Published online: July 13, $2018 \quad \begin{aligned} & \text { DOI: 10.1159/000491722 } 2018 \text { The Author(s). Published by S. Karger AG, Basel } \\ & \text { www.karger.com/cpb }\end{aligned}$ Zhou et al.: FNDC5 Attenuates Liver Fibrosis}

\section{Introduction}

Liver fibrosis is a general pathological process for most of liver diseases. Obesity-related liver disease, particularly nonalcoholic fatty liver disease (NAFLD) results in progressive fibrosis, cirrhosis, end-stage liver disease, and increased incidence of hepatocellular carcinoma $[1,2]$. Hepatic stellate cells (HSCs) are the primary source of fibrogenic cells and are involved in the liver fibrogenesis. Upon liver injury, quiescent HSCs transform quiescent stage to active stage [3]. Activation of HSCs plays a major role in the process of liver fibrosis [4-6]. Studies in rodent models of chronic liver disease suggest that fibrotic extracellular matrix can be remodeled and near-normal hepatic architecture regenerated upon cessation of injury [7]. Termination of fibrogenic processes may allow the reversal of progressive fibrosis and even cirrhosis [8].

Fibronectin type III domain-containing protein 5 (FNDC5) is a novel myokine, and is known to mediate some beneficial effects of exercise via browning of white adipose tissue [9]. Irisin can be released by the cleavage of the extracellular domain of FNDC5 and promote the browning of white adipose tissue [10]. It has been observed that irisin inhibits hepatic gluconeogenesis and increases glycogen synthesis in type 2 diabetic mice and hepatocytes [11]. We have shown that either FNDC5 overexpression or irisin ameliorates glucose/lipid metabolic derangements and enhances lipolysis in obesity [12]. Moreover, FNDC5 alleviates hepatosteatosis by restoring AMPK/mTOR-mediated autophagy, fatty acid oxidation, and lipogenesis in mice [13]. However, whether FNDC5 is involved in the process of liver fibrosis is unknown. The present study is designed to determine the effects of FNDC5 on liver fibrosis and underline mechanisms.

\section{Materials and Methods}

\section{Animal model}

Male FNDC5\% mice on a C57BL/6 background and wild-type (WT) mice were obtained from Nanjing BioMedical Research Institute (Nanjing University, Nanjing, China). Chronic high fat diet (HFD) feeding is used as an efficient tool to simulate clinical NAFLD and associated hepatic fibrosis [14]. Long-term HFD feeding induces the pathological changes including visceral obesity, inflammation, hyperlipidemia and hepatic fibrosis which are similar to that of the human NAFLD [15]. It has been reported that all the rats developed perisinosodial fibrosis after 24 weeks' HFD feeding [14]. Similar results were observed in mice $[16,17]$. These reports suggested that either FNDC5 $\%$ or WT mice at the age of 6 weeks were randomly divided into two groups, which were respectively fed a normal chow served as a normal control group (Ctrl, $14.7 \mathrm{~kJ} / \mathrm{g}, 13 \%$ of energy as fat) or a high fat diet (HFD, $21.8 \mathrm{~kJ} / \mathrm{g}$, 60\% of energy as fat) for 26 weeks. All procedures were performed in accordance with the standards in the guidelines of the Experimental Animal Care and Use Committee of Nanjing Medical University, and conformed to the Guide for the Care and Use of Laboratory Animal published by the US National Institutes of Health (NIH publication, 8th edition, 2011). The mice were housed in a temperature-controlled room with a 12-h light/dark cycle and a free access to tap water and chow. At the end of the experiment, the mouse was euthanized with an overdose of pentobarbital sodium (200 mg/kg, iv).

\section{Culture of $L X-2$ cells}

LX-2 cells, a human hepatic stellate cell line, were obtained from Merck Millipore Corporation, Billerica, MA, USA), and were commonly used for analysis of hepatic fibrosis [18]. The cells were grown in Dulbecco's modified Eagle's medium (DMEM) supplemented with 10\% FBS and 1\% penicillin/streptomycin, and were incubated in a humidified atmosphere of $5 \% \mathrm{CO}_{2}$ and $95 \% \mathrm{O}_{2}$ at $37^{\circ} \mathrm{C}$ [19] .

\section{Culture of primary HSCs}

Primary HSCs from C57BL6 mice at the age of 6 weeks were isolated by a combination of pronase collagenase digestion, density gradient centrifugation, and centrifugal elutriation as previously described [20]. The cells were cultured in DMEM containing 10\% FBS and 1\% penicillin/streptomycin. Purity of HSC 


\section{Cellular Physiology Cell Physiol Biochem 2018;48:227-236 \begin{tabular}{l|l} 
DOI: $10.1159 / 000491722$ & \\
and Biochemistry Published online: July 13, 2018 & $\begin{array}{l}\text { O 2018 The Author(s). Published by S. Karger AG, Basel } \\
\text { www.karger.com/cpb }\end{array}$
\end{tabular} \\ Zhou et al.: FNDC5 Attenuates Liver Fibrosis}

was assessed by immunohistochemistry for desmin (a marker of myofibroblasts), or $\alpha$-smooth muscle actin $(\alpha-\mathrm{SMA})$ (a marker of a population of more differentiated myofibroblasts).

\section{OxLDL treatment}

Oxidized low-density lipoproteins (oxLDL) is well known to stimulate the synthesis of collagen types I and III and fibronectin of cultured HSCs, and was utilized to produce a cell fibrosis model [21]. Upon reaching 70\% confluence, the LX-2 cells or primary HSCs were incubated with PBS or oxLDL $(10 \mu \mathrm{g} / \mathrm{mL}$ ) for $24 \mathrm{~h}$ [22]. The ox-LDL was purchased from Yesen Biotechnology (Shanghai, China).

\section{Western blot}

Samples were homogenized and extracted. Total protein was measured with a protein assay kit (BCA; Pierce, Santa Cruz, CA, USA). Equal amounts of total protein were separated in sodium-dodecyl-sulfatepolyacrylamide gel electrophoresis (SDS-PAGE) and transferred to polyvinylidene difluoride (PVDF) membrane. The bands were visualized by enhanced chemiluminescence (Millipore, Billerica, MA, USA) and quantified by scanning densitometry. Antibody against FNDC5 was purchased from Abcam (Cambridge, MA, USA). Antibodies against collagen-I, collagen-III, connective tissue growth factor (CTGF), $\alpha$-SMA, GAPDH were obtained from Proteintech (Chicago, IL, USA). Antibodies against AMPK, P-AMPK and secondary antibodies were acquired from Santa Cruz (CA, USA).

\section{$R T-P C R$}

Total RNA in samples was exacted using Trizol reagent (Life Technologies, Gaithersburg, MD, USA). RNA concentrations and purity were determined by the optical density at 260 and $280 \mathrm{~nm}$. Reverse transcriptase reactions were performed using the PrimeScript ${ }^{\circledR}$ RT reagent Kits (Takara, Otsu, Shiga, Japan) and ABI PRISM 7500 sequence detection PCR system (Applied Biosystems, Foster City, CA, USA). For quantitative PCR, cDNA fragments were subjected to SYBR Green RT-PCR (Takara Biotechnology Co., Ltd., Tokyo, Japan) with Stepone Plus system. Quantitative measurements were obtained using the $\Delta \Delta C T$ method and normalized to the expression of GAPDH.

\section{Histological evaluation}

Livers of mice were rinsed with PBS and set at $4 \%$ buffered formaldehyde for $24 \mathrm{~h}$. Parafn-embedded tissues were cut into $5 \mu \mathrm{m}$ sections with a cryostat (Leica, Solms, Germany). The sections were stained with hematoxylin and eosin (H\&E). Furthermore, sections were subjected to Masson's trichrome staining [23] or Sirius red staining to evaluate liver fibrosis [24].

\section{Measurement of triglyceride, cholesterol, ALT and AST}

Serum triglyceride (TG), total cholesterol (TCH), alanine transaminase (ALT) and aspartate aminotransferase (AST) levels were evaluated with commercial kits (Nanjing Jiancheng Bioengineering Institute, Nanjing, Jiangsu, China).

\section{Chemicals}

FNDC5 was bought from Sigma Co. (St. Louis, MO, USA). Compound C (CC) was obtained from MedChem Express (Greenville, SC, USA).

\section{Statistical Analysis}

One-way and two-way ANOVA were used for data analysis of more than two groups followed by Bonferroni's post hoc analysis. All data were expressed as mean \pm SEM. A value of $\mathrm{P}<0.05$ was considered statistically significant.

\section{Results}

General data of WT and FNDC5\% mice

FNDC5 deficiency exaggerated the increases in body weight (BW), liver weight (LW), fat weight (FW), LW/BW and FW/BW in mice with HFD, but not in mice with normal diet. 


\section{Cellular Physiology Cell Physiol Biochem 2018;48:227-236 \begin{tabular}{c|c} 
DOI: 10.1159/000491722, & $\begin{array}{l}\text { O 2018 The Author(s). Published by S. Karger AG, Basel } \\
\text { www.karger.com/cpb }\end{array}$
\end{tabular} \\ Zhou et al.: FNDC5 Attenuates Liver Fibrosis}

However, FNDC5 deficiency had no significant effect on food intake in mice with normal diet or HFD. FNDC5 gene deletion increased the TG and TCH levels in serum and liver in mice with normal diet, and magnified the HFD-induced increases in the TG and TCH levels in serum and liver. Furthermore, FNDC5 deficiency had no significant effects on serum ALT and AST activity in mice with normal diet, but aggravated HFD-induced increases in serum ALT and AST activity (Table 1).

\section{FNDC5 deficiency aggravates HFD-induced liver fibrosis in mice}

HFD had no significant effects on the FNDC5 mRNA and protein expressions in mouse liver (Fig. 1A). Efficiency of FNDC5 gene deletion has been identified in our recent study [25], and was further confirmed by the disappeared FNDC5 mRNA and protein expressions in the present study (Fig. 1A). H\&E staining showed that FNDC5 deficiency aggravated HFD-induced fat accumulation and structure disorder in liver (Fig. 1B). Masson's staining revealed obvious sinusoidal fibrosis in the liver of HFD-fed FNDC5\% mice (Fig. 1C). Sirius red staining showed that the pericellular fibrosis induced by HFD was exacerbated by FNDC5 gene deletion (Fig. 1D).

\section{FNDC5 deficiency exacerbates HFD-induced HSCs activation in mouse liver}

Activated HSCs are the main source of myofibroblasts that contributes to collagen accumulation in the development of liver fibrosis [4]. HFD increased the deposition of extracellular matrix (ECM) evidenced by the increased collagen-I and collagen-III mRNA and protein expressions, which were exacerbated in the liver of FNDC5 1- mice (Fig. 2A). $\alpha$-SMA is a classic feature of activated HSCs and used as a marker of HSCs activation [26]. FNDC5 deficiency aggravated the HFDinduced activation of HSCs evidenced by the upregulation of $\alpha$-SMA mRNA and protein expressions in liver (Fig. 2B). CTGF (CCN2) is recognized as a key player in the onset of fibrosis in various tissues [27]. HFD-induced upregulation of CTGF mRNA and protein expressions was amplified in the liver of $\mathrm{FNDC}^{\%} \%$ mice (Fig. 2C).

Table 1. General data of WT and $\mathrm{FNDC}^{\%}$ mice. ALT, alanine transaminase; AST, aspartate aminotransferase; TG, triglyceride; $\mathrm{TCH}$, total cholesterol. Values are mean \pm S.E.M. ${ }^{*} \mathrm{P}<0.05$ vs. $\mathrm{WT}$. $\dagger \mathrm{P}<0.05$ vs. Ctrl. $\mathrm{n}=6$ per group

\begin{tabular}{lcccc}
\hline & \multicolumn{2}{c}{ WT } & \multicolumn{2}{c}{ FNDC5 $\%$} \\
\hline & Ctrl & HFD & Ctrl & HFD \\
Body weight (BW, g) & $31.5 \pm 0.6$ & $37.8 \pm 1.0 \dagger$ & $32.9 \pm 1.4$ & $47.6 \pm 1.3^{* \dagger}$ \\
Liver weight (LW, g) & $1.40 \pm 0.06$ & $1.82 \pm 0.12 \dagger$ & $1.44 \pm 0.03$ & $2.62 \pm 0.15^{* \dagger}$ \\
LW/BW (\%) & $4.46 \pm 0.14$ & $4.80 \pm 0.22 \dagger$ & $4.42 \pm 0.15$ & $5.48 \pm 0.19^{* \dagger}$ \\
Fat weight (FW, g) & $1.60 \pm 0.08$ & $3.29 \pm 0.12 \dagger$ & $1.72 \pm 0.09$ & $5.49 \pm 0.18^{* \dagger}$ \\
FW/BW (\%) & $5.08 \pm 0.20$ & $8.69 \pm 0.18 \dagger$ & $5.23 \pm 0.15$ & $11.53 \pm 0.28^{* \dagger}$ \\
Food intake (g/day) & $4.76 \pm 0.20$ & $4.38 \pm 0.18$ & $4.89 \pm 0.17$ & $4.68 \pm 0.20$ \\
Food intake (kJ/day) & $70.0 \pm 2.9$ & $95.4 \pm 4.0 \dagger$ & $71.9 \pm 2.5$ & $101.9 \pm 4.4$ \\
Liver TG (mg/g) & $1.79 \pm 0.09$ & $2.45 \pm 0.15 \dagger$ & $2.08 \pm 0.11^{*}$ & $4.20 \pm 0.23^{* \dagger}$ \\
Liver TCH (mg/g) & $9.6 \pm 1.1$ & $18.9 \pm 1.5 \dagger$ & $12.9 \pm 1.0^{*}$ & $35.9 \pm 1.5^{* \dagger}$ \\
Serum TG (mM) & $1.02 \pm 0.06$ & $1.74 \pm 0.08 \dagger$ & $1.41 \pm 0.15^{*}$ & $2.62 \pm 0.09^{* \dagger}$ \\
Serum TCH (mM) & $3.07 \pm 0.09$ & $5.13 \pm 0.14 \dagger$ & $3.55 \pm 0.16^{*}$ & $6.72 \pm 0.27^{* \dagger}$ \\
Serum ALT (IU/L) & $26.6 \pm 1.9$ & $57.5 \pm 2.6 \dagger$ & $20.9 \pm 1.7$ & $128.7 \pm 4.1^{* \dagger}$ \\
Serum AST (IU/L) & $43.5 \pm 3.4$ & $68.7 \pm 7.3 \dagger$ & $34.7 \pm 4.8$ & $137.4 \pm 10.5^{* \dagger}$ \\
\hline
\end{tabular}

Fig. 1. FNDC5 deficiency aggravates HFD-induced liver fibrosis in mice. A, FNDC5 mRNA and protein expressions in liver. $\mathrm{B}$, representative images of HE staining showing lipid droplets and structure disorder in liver sections. C, representative images of Masson's staining showing fibrosis in liver sections. D, representative images of Sirius Red staining showing collagenous fibers in liver sections. Values are mean \pm SE. $* \mathrm{P}<0.05$ vs. WT. $\mathrm{n}=6$ per group.

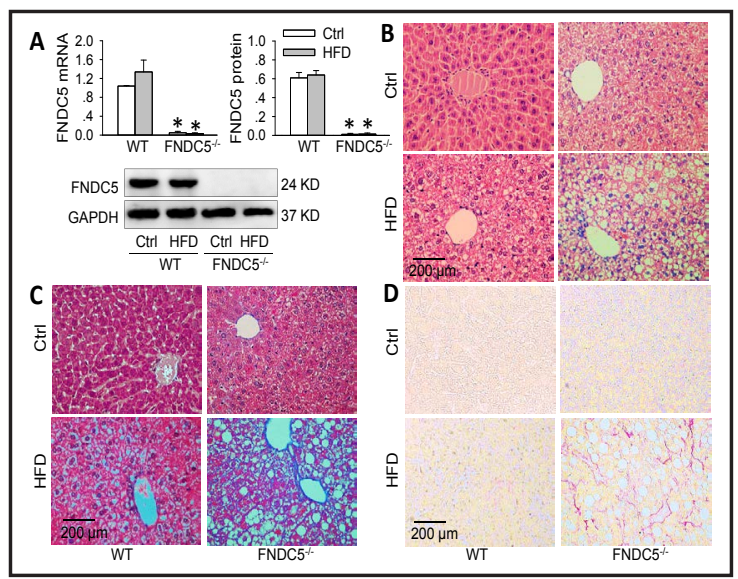




\section{Cellular Physiology Cell Physiol Biochem 2018;48:227-236 \begin{tabular}{l|l|l} 
and BOI: 10.1159/000491722 & $\begin{array}{l}\text { (c) } 2018 \text { The Author(s). Published by S. Karger AG, Basel } \\
\text { www.karger.com/cpb }\end{array}$
\end{tabular}

\section{FNDC5 deficiency enhances HFD-induced AMPK inhibition in mouse liver}

It is well known that inactivation of AMPK promotes hepatic fibrogenesis while its activation may restrain this process [26]. Phosphorylation of Thr172 at $\alpha$ subunit of AMPK increases its activity of AMPK by 2-3 orders of magnitude [28]. Thus, the AMPK phosphorylation in FNDC5 $\%$ mice were examined. Either HFD or FNDC5 gene deletion had no significant effects on AMPK expression, but FNDC5 deficiency enhanced HFD-induced inhibition of AMPK phosphorylation in liver (Fig. 2D).

FNDC5 inhibits HSCs activation and stimulates AMPK phosphorylation in oxLDL-treated primary HSCS

OxLDL is extensively used as an in vitro model for HSCs activation and fibrosis [22, 29, 30]. Based on our findings that FNDC5 deficiency exacerbated HFD-induced liver fibrosis in mice, we examined the effects of different concentrations of FNDC5 on HSCs activation and AMPK phosphorylation in oxLDL-treated primary mouse HSCs. Administration of oxLDL had no significant effects on FNDC5 expression in the primary HSCs from WT and FNDC5\% mice (Fig. 3A). Exogenous FNDC5 reduced $\alpha$-SMA mRNA and protein expressions (Fig. 3B), but increased the AMPK phosphorylation in oxLDL-treated primary mouse HSCs, almost reaching its maximal effects at the concentration of $100 \mathrm{nM}$ (Fig. 3C).

FNDC5 alleviates oxLDL-induced fibrosis in oxLDL-treated primary HSCs

Exogenous FNDC5 stimulated AMPK phosphorylation, and prevented oxLDL-induced inhibition in AMPK phosphorylation in primary mouse HSCs (Fig. 4A). FNDC5 inhibited $\alpha$-SMA, CTGF, collagen-I, and collagen-III expressions in oxLDL-treated primary mouse HSCs, but had no significant effects in vehicle-treated primary mouse HSCs (Fig. 4B-4D).

Fig. 2. FNDC5 deficiency exacerbates the HFD-induced HSCs activation, CTGF expressions, ECM deposition and AMPK phosphorylation inhibition in mouse liver. A, mRNA and protein expressions of collagen $\mathrm{I}$ and collagen III. B, $\alpha$-SMA mRNA and proteins. C, CTGF mRNA and protein expressions. D, AMPK phosphorylation. Values are mean \pm SE. ${ }^{*} \mathrm{P}<0.05$ vs. WT. $\dagger \mathrm{P}<0.05$ vs. Ctrl. $\mathrm{n}=4$ per group.

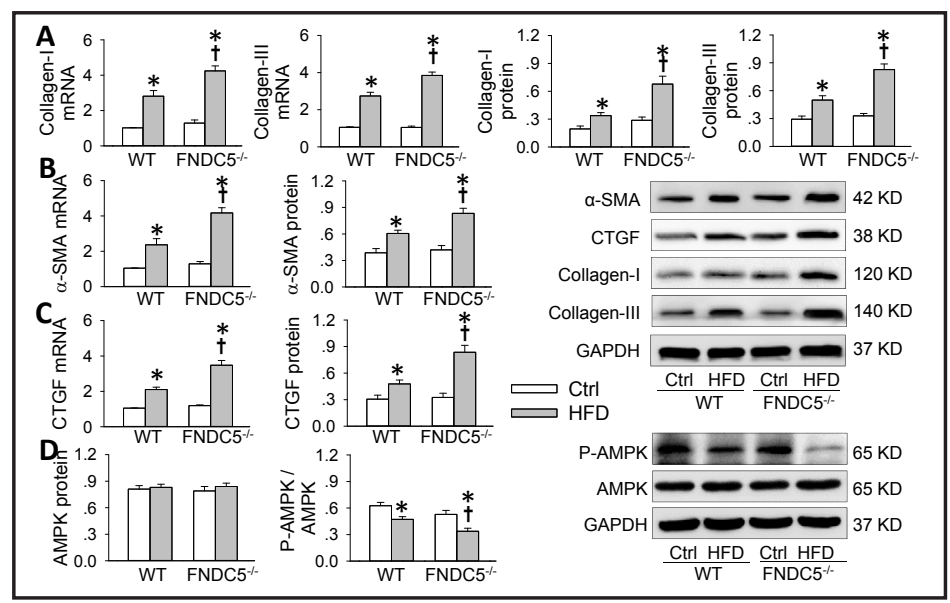

Fig. 3. FNDC5 expression and effects of FNDC5 in mouse HSCs. A, FNDC5 expression in HSCs from WT and FNDC5 $^{-1}$ mice. B, C, D, effects of different concentration of FNDC5 on $\alpha$-SMA expressions (B), AMPK expressions and AMPK phosphorylation (C) in oxLDLtreated primary WT mouse HSCs. Values are mean \pm SE. ${ }^{*} \mathrm{P}<0.05$ vs.

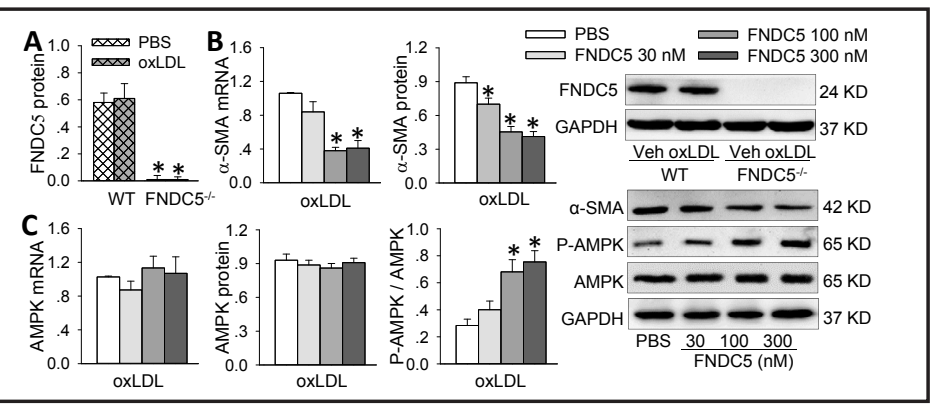
WT or PBS. $n=4$ per group. 
Fig. 4. Effects of FNDC5 on oxLDLinduced AMPK dephosphorylation and fibrosis in primary mouse HSCs. The cells were pretreated with PBS or FNDC5 (100 nM) for $4 \mathrm{~h}$ followed by oxLDL (10 $\mu \mathrm{g} / \mathrm{mL}$ ) for $24 \mathrm{~h}$. A-D, AMPK phosphorylation (A), $\alpha$-SMA expressions (B), CTGF expressions (C) and collagen expressions (D) in HSCs. E, collagen in conditional media of HSCs. GAPDH in HSCs was used as the internal reference. Values are mean \pm SE. ${ }^{*} \mathrm{P}<0.05$ vs. PBS. $\dagger \mathrm{P}<0.05$ vs. Veh. $\mathrm{n}=4$ per group.

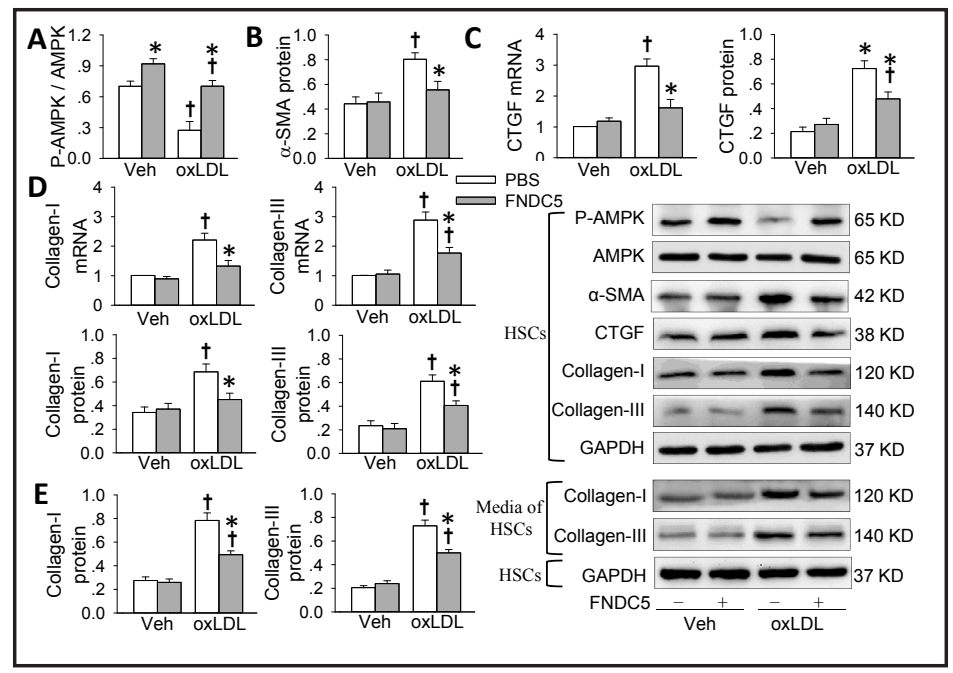

Fig. 5. TGF- $\beta$ expressions in mouse liver and primary mouse HSCs. A, FNDC5 deficiency stimulates TGF- $\beta$ mRNA expression in mouse liver. ${ }^{*} \mathrm{P}<0.05$ vs. WT. $\uparrow \mathrm{P}<0.05$ vs. Ctrl. $\mathrm{B}$, Exogenous FNDC5 reduced the oxLDL-induced upregulation of TGF- $\beta$ mRNA in primary mouse HSCs. The cells were pretreated with PBS or FNDC5 $(100 \mathrm{nM})$ for $4 \mathrm{~h}$ followed by oxLDL $(10 \mu \mathrm{g} / \mathrm{mL})$ for $24 \mathrm{~h} .{ }^{*} \mathrm{P}<0.05$ vs. PBS. $\uparrow \mathrm{P}<0.05$ vs. Veh. Values are mean \pm SE. $n=4$ per group.

Fig. 6. Inhibition of AMPK with compound C (CC) attenuates the protective effects of FNDC5 on the oxLDL-induced AMPK dephosphorylation and fibrosis in LX-2 cells. The cells were pretreated with PBS or FNDC5 (100 nM) plus CC $(25 \mu \mathrm{M})$ for $4 \mathrm{~h}$ followed by oxLDL $(10 \mu \mathrm{g} / \mathrm{mL})$ for 24 h. A, AMPK phosphorylation.

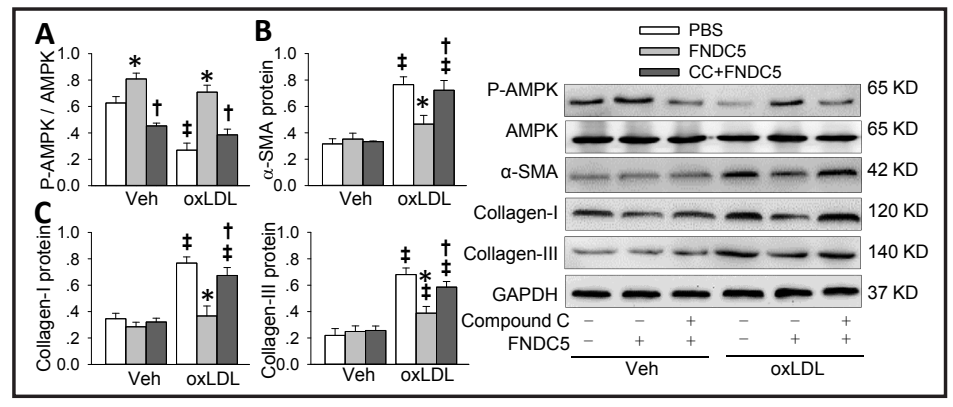
B, $\alpha$-SMA protein expressions. C,

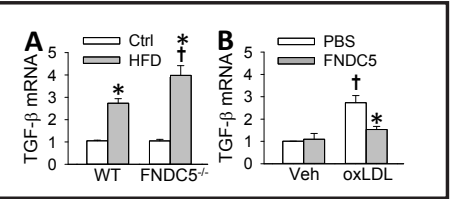
collagen-I and collagen-III protein expressions. Values are mean \pm SE. ${ }^{*} \mathrm{P}<0.05$ vs. PBS. $\dagger \mathrm{P}<0.05$ vs. FNDC5. $\$ \mathrm{P}<0.05$ vs. Veh. $\mathrm{n}=4$ per group.

Furthermore, oxLDL increased collagen-I and collagen-III protein levels in the conditional media of HSCs, which were attenuated by FNDC5 treatment (Fig. 4E).

\section{TGF- $\beta$ expressions in mouse liver and primary mouse HSCS}

TGF- $\beta$ is a potent cytokine to activate HSCs [31, 32], which is inhibited by AMPK [26]. AMPK ameliorates TGF- $\beta$-induced fibrogenic activation in HSCs [33]. FNDC5 deficiency augmented the HFD-induced upregulation of TGF- $\beta$ mRNA levels in mouse liver (Fig. 5A). Exogenous FNDC5 prevented the oxLDL-induced upregulation of TGF- $\beta$ mRNA levels in primary mouse HSCs, but had no significant effects on basal TGF- $\beta$ mRNA levels (Fig. 5B).

\section{Inhibition of AMPK prevents protective roles of FNDC5 in oxLDL-treated LX-2 cells}

CC is a cell-permeable selective AMPK inhibitor, which was used to determine whether AMPK signal would mediate the beneficial effects of FNDC5. Moreover, the experiments were done in human hepatic stellate cell line (LX-2 cells) instead of mouse HSCs. Application of FNDC5 prevented oxLDL-induced AMPK inhibition, HSCs activation and ECM accumulation 


\section{Cellular Physiology Cell Physiol Biochem 2018;48:227-236 \\ \begin{tabular}{l|l} 
DOI: 10.1159/000491722, & $\begin{array}{l}\text { O } 2018 \text { The Author(s). Published by S. Karger AG, Basel } \\
\text { www.karger.com/cpb }\end{array}$
\end{tabular} \\ Zhou et al.: FNDC5 Attenuates Liver Fibrosis}

in LX-2 cells, which were similar to the findings in mouse HSCs. More importantly, the beneficial effects of FNDC5 were almost abolished by CC, indicating that the effects of FNDC5 is primarily mediated by AMPK signaling (Fig. 6A-C).

\section{Discussion}

Hepatic fibrosis is a commonly pathological process for the majority of liver diseases, and often results in cirrhosis, liver failure and portal hypertension [34]. Chronic liver injury results in HSCs activation. The activated HSCs are also known as myofibroblasts, which contributes to liver fibrosis through the accumulation of ECM proteins [34, 35]. The primary novel findings are that FNDC5 deficiency exacerbates HFD-induced AMPK deactivation, HSCs activation and fibrosis in mouse liver. FNDC5 protein prevents oxLDL-induced AMPK deactivation, HSCs activation and ECM deposition in primary mouse HSCs and human LX-2 cells. FNDC5 attenuates liver fibrosis via AMPK phosphorylation-mediated inhibition of HSCs activation.

Activation of HSCs remains a pivotal event in hepatic fibrosis [8, 36]. Transformation of HSC to myofibroblasts is a profibrogenic process that increases $\alpha$-SMA and decreases stored lipid [26]. It is noted that there is a close association between the HFD and oxLDL. Although oxLDL is rapidly removed by Kupffer cells and endothelial cells in the liver [37], intravenous injection of oxLDL induces several changes in the liver microvasculature that may lead to sinusoidal endothelial dysfunction [38], which is considered as an early event in the progression of nonalcoholic steatohepatitis (NASH) [39]. Both HFD and oxLDL play an important role in the initiation of NASH pathogenesis [40]. Thus, the effects of FNDC5 were respectively evaluated in the HFD-induced hepatic fibrosis mice and oxLDL-induced HSCs activation and fibrosis. We found that FNDC5 gene deletion caused severe hepatic fibrosis and HSCs activation in HFD-induced obese mice, indicating the endogenous FNDC5 is critical for attenuating hepatic fibrosis and HSCs activation in obesity. Exogenous FNDC5 protein attenuated oxLDL-induced hepatic fibrosis and HSCs activation not only in mouse HSCs but in human HSCs (LX-2 cells) as well, indicating that exogenous FNDC5 protein can delay or attenuate the process of hepatic fibrosis and HSCs activation. FNDC5 may be a promising therapeutic target for hepatic fibrosis. Recent studies in our lab show that FNDC5 ameliorates hyperlipemia and enhances lipolysis in adipose tissues of obese mice [12], and that FNDC5 prevents HFD-induced hepatic lipid accumulation and impaired fatty acid oxidation in mouse liver [41]. Thus, roles of FNDC5 in improving glucose-lipid metabolism disorder may be partially involved in its beneficial effect on hepatic fibrosis.

AMPK is not only a significant molecule that maintains the homeostasis of energy metabolism, but involved in hepatic fibrosis in liver diseases [26]. Activation of AMPK reduces the HSCs activation in the mouse CCl4 model [42]. Thymoquinone, a phytochemical compound for treating liver diseases, activated AMPK, restrained the expression of $\alpha$-SMA, alleviated thioacetamide-induced hepatic fibrosis and inflammation [43]. In the present study, FNDC5 deficiency exacerbates HFD-induced AMPK deactivation in mouse liver, while administration of FNDC5 prevented oxLDL-induced AMPK deactivation in HSCs. Inhibition of AMPK with compound $\mathrm{C}$ almost abolished the beneficial effects of FNDC5 on oxLDL-induced AMPK deactivation, HSCs activation and ECM deposition in human LX-2 cells. These results indicate that the beneficial effects of FNDC5 on hepatic fibrosis primarily mediated by AMPK signaling and HSCs activation. It is noted that the effects of FNDC5 on hepatic fibrosis in mice in the present study cannot be distinguished from its effects on adiposity, and hepatic steatosis.

In summary, FNDC5 deficiency aggravates HFD-induced liver fibrosis, AMPK deactivation, HSCs activation, and ECM deposition in mouse liver. Administration of FNDC5 attenuates oxLDL-induced AMPK deactivation, HSCs activation and ECM deposition in mice and human HSCs. Inhibition of AMPK prevents the beneficial roles of FNDC5 in attenuating liver fibrosis and HSCs activation. However, the effects of FNDC5 on hepatic fibrosis in vivo 


\section{Cellular Physiology Cell Physiol Biochem 2018;48:227-236 \begin{tabular}{l|l} 
DOI: 10.1159/000491722 & O 2018 The Author(s). Published by S. Karger AG, Basel \\
www.karger.com/cpb
\end{tabular} Zhou et al.: FNDC5 Attenuates Liver Fibrosis}

cannot be distinguished from its effects on adiposity, and hepatic steatosis in the current study. We concluded that FNDC5 attenuates liver fibrosis via AMPK-mediated inhibition of HSC activation. FNDC5 may be a promising therapeutic strategy for hepatic fibrosis.

\section{Acknowledgements}

This study was supported by National Natural Science Foundation of China (91639105, $31571167 \& 91439120)$.

\section{Disclosure Statement}

The authors declare that they have no competing interests.

\section{References}

1 Suriawinata A, Fiel MI: Liver pathology in obesity. Semin Liver Dis 2004;24:363-370.

- Hetherington AM, Sawyez CG, Zilberman E, Stoianov AM, Robson DL, Borradaile NM: Differential lipotoxic effects of palmitate and oleate in activated human hepatic stellate cells and epithelial hepatoma cells. Cell Physiol Biochem 2016;39:1648-1662.

-3 Friedman SL: Hepatic stellate cells: protean, multifunctional, and enigmatic cells of the liver. Physiol Rev 2008;88:125-172.

4 Xu J, Kisseleva T: Bone marrow-derived fibrocytes contribute to liver fibrosis. Exp Biol Med (Maywood) 2015;240:691-700.

5 Yu F, Guo Y, Chen B, Shi L, Dong P, Zhou M, Zheng J: LincRNA-p21 inhibits the Wnt/beta-catenin pathway in activated hepatic stellate cells via sponging microRNA-17-5p. Cell Physiol Biochem 2017;41:1970-1980.

-6 Li B, Cong M, Zhu Y, Xiong Y, Jin W, Wan Y, Zhou Y, Ao Y, Wang H: Indole-3-carbinol induces apoptosis of hepatic stellate cells through K63 de-ubiquitination of RIP1 in rats. Cell Physiol Biochem 2017;41:14811490 .

7 Ellis EL, Mann DA: Clinical evidence for the regression of liver fibrosis. J Hepatol 2012;56:1171-1180.

8 Elpek GO: Cellular and molecular mechanisms in the pathogenesis of liver fibrosis: An update. World J Gastroenterol 2014;20:7260-7276.

-9 Bostrom P, Wu J, Jedrychowski MP, Korde A, Ye L, Lo JC, Rasbach KA, Bostrom EA, Choi JH, Long JZ, Kajimura S, Zingaretti MC, Vind BF, Tu H, Cinti S, Hojlund K, Gygi SP, Spiegelman BM: A PGC1-alpha-dependent myokine that drives brown-fat-like development of white fat and thermogenesis. Nature 2012;481:463468.

10 Liu J: Irisin as an exercise-stimulated hormone binding crosstalk between organs. Eur Rev Med Pharmacol Sci 2015;19:316-321.

11 Liu TY, Shi CX, Gao R, Sun HJ, Xiong XQ, Ding L, Chen Q, Li YH, Wang JJ, Kang YM, Zhu GQ: Irisin inhibits hepatic gluconeogenesis and increases glycogen synthesis via the PI3K/Akt pathway in type 2 diabetic mice and hepatocytes. Clin Sci (Lond) 2015;129:839-850.

-12 Xiong XQ Chen D, Sun HJ, Ding L, Wang JJ, Chen Q Li YH, Zhou YB, Han Y, Zhang F, Gao XY, Kang YM, Zhu GQ: FNDC5 overexpression and irisin ameliorates glucose/lipid metabolic derangements and enhances lipolysis in obesity. Biochim Biophys Acta 2015;1852:1867-1875.

13 Liu TY, Xiong XQ, Ren XS, Zhao MX, Shi CX, Wang JJ, Zhou YB, Zhang F, Han Y, Gao XY, Chen Q, Li YH, Kang YM, Zhu GQ: FNDC5 alleviates hepatosteatosis by restoring AMPK/mTOR-mediated autophagy, fatty acid oxidation, and lipogenesis in mice. Diabetes 2016;65:3262-3275.

14 Xu ZJ, Fan JG, Ding XD, Qiao L, Wang GL: Characterization of high-fat, diet-induced, non-alcoholic steatohepatitis with fibrosis in rats. Dig Dis Sci 2010;55:931-940.

15 Pandey A, Raj P, Goru SK, Kadakol A, Malek V, Sharma N, Gaikwad AB: Esculetin ameliorates hepatic fibrosis in high fat diet induced non-alcoholic fatty liver disease by regulation of Fox01 mediated pathway. Pharmacol Rep 2017;69:666-672. 


\section{Cellular Physiology Cell Physiol Biochem 2018;48:227-236 \begin{tabular}{l|l} 
DOI: 10.1159/000491722, & $\begin{array}{l}\text { O 2018 The Author(s). Published by S. Karger AG, Basel } \\
\text { www.karger.com/cpb }\end{array}$
\end{tabular} \\ Zhou et al.: FNDC5 Attenuates Liver Fibrosis}

16 Zhang Y, Wu B, Zhang H, Ge X, Ying S, Hu M, Li W, Huang Y, Wang L, Chen C, Shan X, Liang G: Inhibition of MD2-dependent inflammation attenuates the progression of non-alcoholic fatty liver disease. J Cell Mol Med 2018;22:936-947.

17 Liang D, Chen H, Zhao L, Zhang W, Hu J, Liu Z, Zhong P, Wang W, Wang J, Liang G: Inhibition of EGFR attenuates fibrosis and stellate cell activation in diet-induced model of nonalcoholic fatty liver disease. Biochim Biophys Acta 2017;1864:133-142.

18 Xu L, Hui AY, Albanis E, Arthur MJ, O’Byrne SM, Blaner WS, Mukherjee P, Friedman SL, Eng FJ: Human hepatic stellate cell lines, LX-1 and LX-2: new tools for analysis of hepatic fibrosis. Gut 2005;54:142-151.

19 Perumal N, Perumal M, Halagowder D, Sivasithamparam N: Morin attenuates diethylnitrosamine-induced rat liver fibrosis and hepatic stellate cell activation by co-ordinated regulation of Hippo/Yap and TGFbeta1/Smad signaling. Biochimie 2017;140:10-19.

20 Thompson KC, Trowern A, Fowell A, Marathe M, Haycock C, Arthur MJ, Sheron N: Primary rat and mouse hepatic stellate cells express the macrophage inhibitor cytokine interleukin-10 during the course of activation In vitro. Hepatology 1998;28:1518-1524.

21 Schneiderhan W, Schmid-Kotsas A, Zhao J, Grunert A, Nussler A, Weidenbach H, Menke A, Schmid RM, Adler G, Bachem MG: Oxidized low-density lipoproteins bind to the scavenger receptor, CD36, of hepatic stellate cells and stimulate extracellular matrix synthesis. Hepatology 2001;34:729-737.

22 Liang D, Chen H, Zhao L, Zhang W, Hu J, Liu Z, Zhong P, Wang W, Wang J, Liang G: Inhibition of EGFR attenuates fibrosis and stellate cell activation in diet-induced model of nonalcoholic fatty liver disease. Biochim Biophys Acta 2017;1864:133-142.

23 Ishak K, Baptista A, Bianchi L, Callea F, De GJ, Gudat F, Denk H, Desmet V, Korb G, MacSween RN: Histological grading and staging of chronic hepatitis. J Hepatol 1995;22:696-699.

-24 Pandey A, Raj P, Goru SK, Kadakol A, Malek V, Sharma N, Gaikwad AB: Esculetin ameliorates hepatic fibrosis in high fat diet induced non-alcoholic fatty liver disease by regulation of Fox01 mediated pathway. Pharmacol Rep 2017;69:666-672.

25 Liu TY, Xiong XQ, Ren XS, Zhao MX, Shi CX, Wang JJ, Zhou YB, Zhang F, Han Y, Gao XY, Chen Q, Li YH, Kang YM, Zhu GQ: FNDC5 alleviates hepatosteatosis by restoring AMPK/mTOR-mediated autophagy, fatty acid oxidation, and lipogenesis in Mice. Diabetes 2016;65:3262-3275.

26 Liang Z, Li T, Jiang S, Xu J, Di W, Yang Z, Hu W, Yang Y: AMPK: a novel target for treating hepatic fibrosis. Oncotarget 2017;8:62780-62792.

27 Bruno G, Cencetti F, Pertici I, Japtok L, Bernacchioni C, Donati C, Bruni P: CTGF/CCN2 exerts profibrotic action in myoblasts via the up-regulation of sphingosine kinase-1/S1P signaling axis: Implications in the action mechanism of TGFbeta. Biochim Biophys Acta 2015;1851:194-202.

28 Carling D: AMPK signalling in health and disease. Curr Opin Cell Biol 2017;45:31-37.

29 Schneiderhan W, Schmid-Kotsas A, Zhao J, Grunert A, Nussler A, Weidenbach H, Menke A, Schmid RM, Adler G, Bachem MG: Oxidized low-density lipoproteins bind to the scavenger receptor, CD36, of hepatic stellate cells and stimulate extracellular matrix synthesis. Hepatology 2001;34:729-737.

-30 Kang Q Chen A: Curcumin eliminates oxidized LDL roles in activating hepatic stellate cells by suppressing gene expression of lectin-like oxidized LDL receptor-1. Lab Invest 2009;89:1275-1290.

-31 Yu F, Yang J, Huang K, Pan X, Chen B, Dong P, Zheng J: The epigenetically-regulated microRNA-378a targets TGF-b2 in TGF-b1-treated hepatic stellate cells. Cell Physiol Biochem 2016;40:183-194.

32 Kim MJ, Park SA, Kim CH, Park SY, Kim JS, Kim DK, Nam JS, Sheen YY: TGF-b type I receptor kinase inhibitor EW-7197 suppresses cholestatic liver fibrosis by inhibiting HIF1a-induced epithelial mesenchymal transition. Cell Physiol Biochem 2016;38:571-588.

-33 Lim JY, Oh MA, Kim WH, Sohn HY, Park SI: AMP-activated protein kinase inhibits TGF-beta-induced fibrogenic responses of hepatic stellate cells by targeting transcriptional coactivator p300. J Cell Physiol 2012;227:1081-1089.

34 Trautwein C, Friedman SL, Schuppan D, Pinzani M: Hepatic fibrosis: Concept to treatment. J Hepatol 2015;62:S15-S24.

-35 Koyama Y, Brenner DA: New therapies for hepatic fibrosis. Clin Res Hepatol Gastroenterol 2015;39 Suppl 1:S75-S79.

-36 Ni MM, Xu T, Wang YR, He YH, Zhou Q, Huang C, Meng XM, Li J: Inhibition of IRF3 expression reduces TGFb1-induced proliferation of hepatic stellate cells. J Physiol Biochem 2016;72:9-23. 


\section{Cellular Physiology Cell Physiol Biochem 2018;48:227-236 \begin{tabular}{l|l} 
DOI: 10.1159/000491722 & $\begin{array}{l}\text { O 2018 The Author(s). Published by S. Karger AG, Basel } \\
\text { www.karger.com/cpb }\end{array}$ \\
\hline
\end{tabular} \\ Zhou et al.: FNDC5 Attenuates Liver Fibrosis}

-37 Van Berkel TJ, De Rijke YB, Kruijt JK: Different fate in vivo of oxidatively modified low density lipoprotein and acetylated low density lipoprotein in rats. Recognition by various scavenger receptors on Kupffer and endothelial liver cells. J Biol Chem 1991;266:2282-2289.

-38 Oteiza A, Li R, McCuskey RS, Smedsrod B, Sorensen KK: Effects of oxidized low-density lipoproteins on the hepatic microvasculature. Am J Physiol Gastrointest Liver Physiol 2011;301:G684-G693.

-39 Pasarin M, La M, V, Gracia-Sancho J, Garcia-Caldero H, Rodriguez-Vilarrupla A, Garcia-Pagan JC, Bosch J, Abraldes JG: Sinusoidal endothelial dysfunction precedes inflammation and fibrosis in a model of NAFLD. PLoS One 2012;7:e32785.

-40 Yimin, Furumaki H, Matsuoka S, Sakurai T, Kohanawa M, Zhao S, Kuge Y, Tamaki N, Chiba H: A novel murine model for non-alcoholic steatohepatitis developed by combination of a high-fat diet and oxidized lowdensity lipoprotein. Lab Invest 2012;92:265-281.

41 Liu TY, Xiong XQ, Ren XS, Zhao MX, Shi CX, Wang JJ, Zhou YB, Zhang F, Han Y, Gao XY, Chen Q, Li YH, Kang YM, Zhu GQ: FNDC5 alleviates hepatosteatosis by restoring AMPK/mTOR-mediated autophagy, fatty acid oxidation, and lipogenesis in Mice. Diabetes 2016;65:3262-3275.

42 da Silva MA, barca-Quinones J, Guigas B, Viollet B, Starkel P, Horsmans Y, Leclercq IA: Development of hepatic fibrosis occurs normally in AMPK-deficient mice. Clin Sci (Lond) 2009;118:411-420.

43 Bai T, Yang Y, Wu YL, Jiang S, Lee JJ, Lian LH, Nan JX: Thymoquinone alleviates thioacetamideinduced hepatic fibrosis and inflammation by activating LKB1-AMPK signaling pathway in mice. Int Immunopharmacol 2014;19:351-357. 